\title{
Synthesis of Mesoporous Lithium Titanate Thin Films and Monoliths as an Anode Material for High-Rate Lithium-Ion Batteries
}

\author{
Fadime Mert Balcl, ${ }^{[a]}$ Ömer Ulaş Kudu, ${ }^{[b]} E^{2}$ Cla Ylmaz, $^{*[b]}$ and Ömer Dag ${ }^{*[a]}$
}

Abstract: Mesoporous $\mathrm{Li}_{4} \mathrm{Ti}_{5} \mathrm{O}_{12}$ (LTO) thin film is an important anode material for lithium-ion batteries (LIBs). Mesoporous films could be prepared by self-assembly processes. A molten-salt-assisted self-assembly (MASA) process is used to prepare mesoporous thin films of LTOs. Clear solutions of $\mathrm{CTAB}, \mathrm{P} 123, \mathrm{LiNO}_{3}, \mathrm{HNO}_{3}$, and $\mathrm{Ti}\left(\mathrm{OC}_{4} \mathrm{H}_{9}\right)_{4}$ in ethanol form gellike meso-ordered films upon either spin or spray coating. In the assembly process, the CTAB/P123 molar ratio of 14 is required to accommodate enough salt species in the mesophase, in which the Li/P123 ratio can be varied between molar ratios of 28 and 72 . Calcination of the meso-ordered films produces transparent mesoporous spinel LTO films that are abbreviated as Cxx-yyy-zzz or CAxx-yyy-zzz (C=calcined,
$\mathrm{CA}=$ calcined-annealed, $x x=\mathrm{Li}^{\mathrm{l}} / \mathrm{P} 123$ molar ratio, and $y y y=$ calcination and $z z z=$ annealing temperatures in Celsius) herein. All samples were characterized by using XRD, TEM, $\mathrm{N}_{2}$-sorption, and Raman techniques and it was found that, at all compositions, the LTO spinel phase formed with or without an anatase phase as an impurity. Electrochemical characterization of the films shows excellent performance at different current rates. The CA40-350-450 sample performs best among all samples tested, yielding an average discharge capacity of $(176 \pm 1) \mathrm{mAhg}^{-1}$ at $\mathrm{C} / 2$ and $(139 \pm 4) \mathrm{mAhg}^{-1}$ at $50 \mathrm{C}$ and keeping $92 \%$ of its initial discharge capacity upon 50 cycles at $C / 2$.

\section{Introduction}

Lithium-ion batteries (LIBs) are attractive energy storage systems due to their high energy and power storage density, and long cycle life. In the last few decades, LIBs have also been considered as appealing alternatives for use in clean energy systems, such as electric and hybrid electric vehicles. ${ }^{[1-5]}$ Graphite is the most commonly used anode material in -*commercial LIBs; however, it has a low $\mathrm{Li}^{+}$diffusion coefficient and high volume change $(\approx 9 \%)$ during $\mathrm{Li}^{+}$intercalation/deintercalation, leading to poor rate capability. Furthermore, it has a low operating potential $\left(<0.2 \mathrm{~V}\right.$ vs. $\left.\mathrm{Li} / \mathrm{Li}^{+}\right)$, which is close to the lithium electroplating potential, and therefore, introduces serious safety issues. ${ }^{[6,7]}$

Recently, spinel $\mathrm{Li}_{4} \mathrm{Ti}_{5} \mathrm{O}_{12}$ (LTO) has attracted significant attention in LIB anode material research for the following reasons: $1)$ it has a high operating potential $\left(\approx 1.55 \mathrm{~V}\right.$ versus $\left.\mathrm{Li} / \mathrm{Li}^{+}\right)$, which is safely away from the reduction potentials of conventional electrolytes and lithium electroplating potential; 2) it

[a] Dr. F. M. Balcı, Prof. Ö. Dag

Department of Chemistry, Bilkent University, 06800 Ankara (Turkey) E-mail:dag@fen.bilkent.edu.tr

[b] Ö. U. Kudu, Prof. E. Yılmaz

Institute of Materials Science and Nanotechnology

National Nanotechnology Research Center (UNAM) Bilkent University, 06800 Ankara (Turkey)

E-mail:yilmaz@unam.bilkent.edu.tr

$\square$ Supporting information for this article can be found under: http://dx.doi.org/10.1002/chem.201604253. faces almost no volume expansion during cycling, which increases its cyclic stability and $\mathrm{Li}^{+}$ion mobility; and 3) it provides a solid-electrolyte interface (SEI) free electrode surface, which makes it more resistant to high-power applications, such as electric vehicles. ${ }^{[8-11]}$ However, LTO has low electronic conductivity $\left(<10^{-12} \mathrm{Scm}\right)$ and a moderate $\mathrm{Li}^{+}$ion diffusion coefficient $\left(10^{-9}-10^{-13} \mathrm{~cm}^{2} \mathrm{~s}^{-1}\right)$, which limit its use in practical high-power applications. ${ }^{[1]]}$ Different approaches have been utilized to reduce the transport path of $\mathrm{Li}^{+}$and electrons, such as nanostructuring, doping, or coating of the LTO materials..$^{[7,12-17]}$ In particular, producing mesoporous LTO materials results in a reduction of the polarization effects and an increased performance at high current rates because the mesoporous structure provides a high specific surface area, narrow pore size distribution, and good permeation. ${ }^{[13]}$ Furthermore, the direct deposition of the synthesized material on the current collector eliminates the necessity of using binders, which are used to enhance mechanical connections between active powder materials in the slurry-casting technique. In addition to limiting effects on the electronic conductivity, since they are insulating, binders also slow down $\mathrm{Li}^{+}$ion exchange between the electrode and electrolyte. ${ }^{[17]}$

There are only a few methods of producing mesoporous LTO materials by using a surfactant template. ${ }^{[18-23]}$ Dag et al. developed a molten-salt-assisted self-assembly (MASA) method with a higher surface area and thinner pore walls by using small nonionic surfactants. ${ }^{[23]}$ In this assembly process, the lithium source, a salt, and a polymerizing titania source can self-assemble nonionic surfactants into mesophases that can be cal- 
cined at higher temperature to produce mesoporous LTO thin films and monoliths. ${ }^{[23]}$ The MASA approach has many advantages over other synthetic methods. One such advantage is that the precursors for both lithium and titanium are very common and one can produce thinner pore walls with a larger surface area in the form of thin films or monoliths.

The MASA process is a new assembly process and can be used to synthesize many other mesoporous materials that have not yet been synthesized. In this assembly process, the key step is the formation of a lyotropic liquid crystalline (LLC) mesophase with the salt and surfactant species. ${ }^{[23-25]}$ Notably, nonionic surfactants, such as oligo(ethylene oxides) and pluronics, can form LLC mesophases by using many different salts as solvents. ${ }^{[26-29]}$ The salts can be alkali metals, alkaline earth metals, transition metals, and lanthanides. ${ }^{[26-30]}$ The determining parameter in the choice of a salt is its low melting point or low deliquescence relative humidity value. ${ }^{[29]}$ The major driving force for the formation of a salt-surfactant mesophase is the high hygroscopicity of the salt. ${ }^{[29]}$ It is also important to note that, upon assembling the salt and surfactant, the melting point and solubility of the salts further decreases and increases, respectively, in a nanoconfined space. ${ }^{[28,31]}$ Adding a charged surfactant to the LLC media further enhances salt uptake of the media that may be necessary to design stable mesoporous materials with those salts as precursors. ${ }^{[32]}$ Furthermore, the addition of polymerizing agents, such as metal alkoxides, into this media does not disturb the mesophase ${ }^{[23-25]}$ that is ready for high-temperature calcination for the synthesis of a desired metal oxide. The MASA approach uses salts as media to assemble surfactants and as a precursor for the synthesis of mixed oxides. $^{[23-25]}$ Many mixed oxides have been synthesized by using the surfactant templating approach; however, the synthesis of some of the mesoporous metal oxides is difficult, either due to fast formation kinetics or because they require very high temperatures at which most templating methods fail. ${ }^{[33-37]}$ Therefore, the use of salts as the metal source for the mesoporous metal oxide and MASA as the assembly process can be beneficial to obtain mesoporous metal oxide thin films for various applications.

Herein, we have targeted an anode material (LTO) with a high power density for LIBs by using a MASA approach that employs P123 (a triblock copolymer, $\mathrm{PEO}_{20}-\mathrm{PPO}_{70}-\mathrm{PEO}_{20}$; $\mathrm{PEO}=$ polyethylene oxide, $\mathrm{PPO}=$ polypropylene oxide) and $\mathrm{C}_{16} \mathrm{H}_{33} \mathrm{~N}\left(\mathrm{CH}_{3}\right)_{3} \mathrm{Br}(\mathrm{CTAB})$ as structure-directing agents and $\mathrm{LiNO}_{3}$ and $\mathrm{Ti}\left(\mathrm{OC}_{4} \mathrm{H}_{9}\right)_{4}(\mathrm{TTB})$ as the metal precursors. Relative to oligo(ethylene oxide) nonionic surfactants, pluronics may provide larger pores and better crystalline pore walls, which may be beneficial for charging and discharging of these materials. The synthetic conditions were optimized by varying the $\mathrm{Li}^{\mathrm{l}}$ or $\mathrm{Ti}^{\mathrm{iV}} /$ $\mathrm{P} 123$ and CTAB/P123 molar ratios by keeping the $\mathrm{Li}^{\mathrm{l}} / \mathrm{Ti}^{\mathrm{IV}}$ molar ratio constant. The materials, during all steps of the synthesis, have been characterized by means of spectroscopy, diffraction, microscopy, and electrochemical measurements.

b)
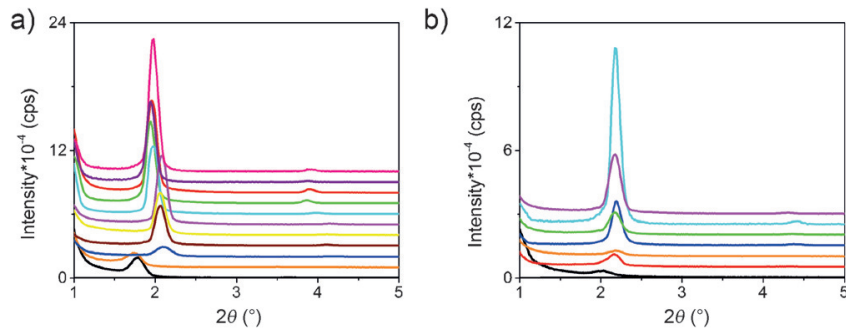

Figure 1. Small-angle XRD patterns of the fresh samples: a) with increasing CTAB/P123 molar ratio (bottom to top: $4,5,6,7,8,10,11,12,13$, and 14) at a constant $\mathrm{Li}^{\mathrm{I}} / \mathrm{P} 123$ molar ratio of 28 and $\mathrm{Li}^{\mathrm{l}} / \mathrm{Ti}^{\mathrm{iV}}$ molar ratio of 0.8 , and b) with increasing Li'/P123 molar ratio (bottom to top: 20, 28, 36, 40, 52, 60, and 72 ) at a constant CTAB/P123 molar ratio of 14 and $\mathrm{Li}^{\mathrm{l}} / \mathrm{Ti}^{\mathrm{IV}}$ of $4 / 5$.

\section{Results and Discussion}

Mesoporous LTO thin films and monoliths were prepared by using the MASA approach by optimizing the reaction conditions. ${ }^{[21]}$ In place of 10-lauryl ether $\left(\mathrm{C}_{12} \mathrm{H}_{25}\left(\mathrm{OCH}_{2} \mathrm{CH}_{2}\right)_{10} \mathrm{OH}\right.$; $\left.\mathrm{C}_{12} \mathrm{E}_{10}\right), \mathrm{P} 123\left(\mathrm{EO}_{20} \mathrm{PO}_{70} \mathrm{EO}_{20} ; \mathrm{EO}=\right.$ ethylene oxide, $\mathrm{PO}=$ propylene oxide) was used as the nonionic surfactant in the assembly process. P123 has many advantages over $\mathrm{C}_{12} \mathrm{E}_{10}$ in the synthesis, as well as in the surface and pore structure of the LTO. By the MASA approach, two parameters are critical and ne controlled and optimized: the amounts of CTAB the me salt uptake of factant in the media. ${ }^{[32]}$ In the synthesis, two surfactants (P123 and $(T A B)$ were collectively used as the structure-directing agents, and the amounts of $\mathrm{CTAB}$ and $\mathrm{LiNO}_{3}$ were optimized by preparing a number of samples and analyzing them by means of XRD and $\mathrm{N}_{2}$-sorption measurements. The CTAB/P123, $\mathrm{Li}^{\mathrm{i}} / \mathrm{P} 123$, and $\mathrm{Ti}^{\mathrm{IV}} / \mathrm{P} 123$ molar ratios were varied from 4 to 14 , 20 to 72 , and 25 to 90 , respectively, while keeping the $\mathrm{Li}^{\mathrm{l}} / \mathrm{Ti}^{\mathrm{iV}}$ ar ratio constant $(0.8$, stoichiometric ratio with respect to . The idea was to minimize the amount of surfactant necas we synthesis of well-defined mesoporous LTO films, self-assembly process. The mixture of all ingredients forms a clear solution that can be spin coated over any substrate to form the thin films or spray coated to obtain large quantities of samples as monoliths. To simplify labeling of the samples, we designated the fresh samples as Fxxyy, in which $F$ represented fresh samples and $x x$ and $y y$ represented the CTAB/ P123 and Li/P123 molar ratios, respectively. The calcined samwere labeled as Zxx-yyy-zzz, in which Z was C (calcined) or ed and annealed) and $x x$, $y y y$, and $z z z$ represented temperatures, respectively.

Figure 1 a shows a series of XRD patterns recorded on fresh Fxx28 samples, in which $x x$ (CTAB/P123 molar ratio) was varied from 4 to 14 . The intensity of the XRD lines gradually increases with increasing $C T A B / P 123$ molar ratio in the samples. Interestingly, the unit cell dimension responds to the CTAB/P123 molar ratio, and first decreases with an increase in the molar ratio and then increases upon further increasing this ratio. The ob- 
served changes can be considered as either a phase change or a packing number change in the surfactant domain of the mesophases; both are known phenomena in surfactant chemistry. ${ }^{[38,39]}$ Therefore, we have chosen the maximum CTAB/ P123 molar ratio for further investigations. Also, a high CTAB/ P123 ratio is necessary to stabilize the mesophases at high salt concentrations. One can increase the salt content of the mesophase by increasing the CTAB concentration of the salt-surfactant mesophases. Figure $1 \mathrm{~b}$ shows the XRD patterns with varying amounts of $\mathrm{Li}^{\prime}$ and $\mathrm{Ti}^{\mathrm{IV}}$ in the samples, prepared by using a CTAB/P123 molar ratio of 14 . In all compositions, the mesophase is preserved, with some changes in their XRD patterns.

The fresh samples were immediately calcined at $350^{\circ} \mathrm{C}$ and annealed at $400^{\circ} \mathrm{C}$ for $2 \mathrm{~h}$. Figure 2 displays a set of nitrogen
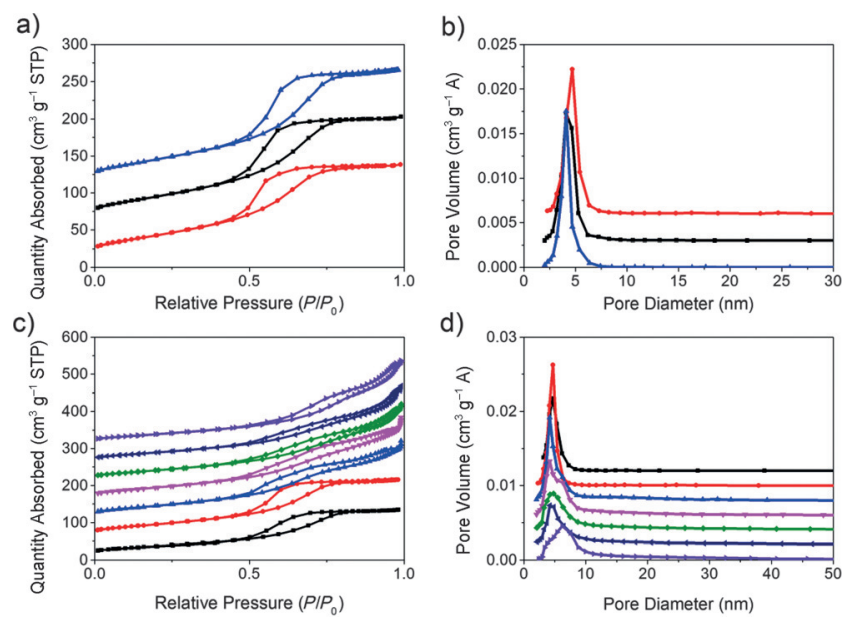

Figure 2. Nitrogen (77 K) sorption isotherms of a) CA28-350-400 with increasing CTAB/P123 ratios (bottom to top) of 4,9 , and 14 ; b) desorption branch pore size distribution plots of the same samples as those shown in a); c) nitrogen (77 K) sorption isotherms of CA20-350-400, CA28-350-400, CA36-350-400, CA40-350-400, CA52-350-400, CA60-350-400, and CA72-350400 (bottom to top) with increasing Li/P123 molar ratio; and d) desorption branch pore size distribution plots of the same samples as those shown in $\mathrm{c}$ ). sorption isotherms and pore size distribution plots with varying amounts of $\mathrm{CTAB}$ and $\mathrm{LiNO}_{3}$. Slight changes were observed after increasing the CTAB/P123 molar ratio, but the changes were more notable after increasing the Li/P123 molar ratio. Although the pores of the calcined samples are small and uniform at low salt concentrations, they are large and less uniform at high salt concentrations (Figure 2). The CTAB/P123 molar ratio is critical for samples with high salt contents (the CTAB/ P123 ratio should be kept high to accommodate large amounts of $\mathrm{LiNO}_{3}$ in the fresh samples); therefore, we investigated the calcined samples by varying the Li/P123 ratio and by keeping the CTAB/P123 ratio constant at 14 . The surface area also responds to the amount of $\mathrm{Li}^{\mathrm{l}}$ in the samples, for which the largest surface area $\left(163 \mathrm{~m}^{2} \mathrm{~g}^{-1}\right)$ was observed for CA28-350-400 and the surface area in the samples gradually decreased to $139 \mathrm{~m}^{2} \mathrm{~g}^{-1}$ for CA72-350-400. The pores gradually expand and crystallization of the pore walls is enhanced at the expense of surface area with increasing annealing temperature. The typical surface area, at $400^{\circ} \mathrm{C}$, is around $139-163 \mathrm{~m}^{2} \mathrm{~g}^{-1}$ and drops to $72 \mathrm{~m}^{2} \mathrm{~g}^{-1}$ at $500^{\circ} \mathrm{C}$. The other sorption parameters are given in Table 1.

Figure 3 a shows the set of XRD patterns of the samples prepared at $450{ }^{\circ} \mathrm{C}$ with varying Li/P123 molar ratios. The diffraction lines can be indexed to spinel LTO, except in first two samples (low compositions), which contain a small amount of

\begin{tabular}{|c|c|c|c|}
\hline Sample & $\begin{array}{l}\text { BET SA } \\
{\left[\mathrm{m}^{2} \mathrm{~g}^{-1}\right]}\end{array}$ & $\begin{array}{l}\text { PS } \\
{[\AA]}\end{array}$ & $\begin{array}{l}\text { PV } \\
{\left[\mathrm{cm}^{3} \mathrm{~g}^{-1} \AA^{-1}\right]}\end{array}$ \\
\hline $28-X$ & 163 & 47 & 0.76 \\
\hline $36-X$ & 163 & 41 & 0.47 \\
\hline $40-X$ & 161 & 42 & 0.31 \\
\hline $52-X$ & 148 & 46 & 0.23 \\
\hline $60-X$ & 141 & 45 & 0.24 \\
\hline $72-X$ & 139 & 64 & 0.29 \\
\hline
\end{tabular}
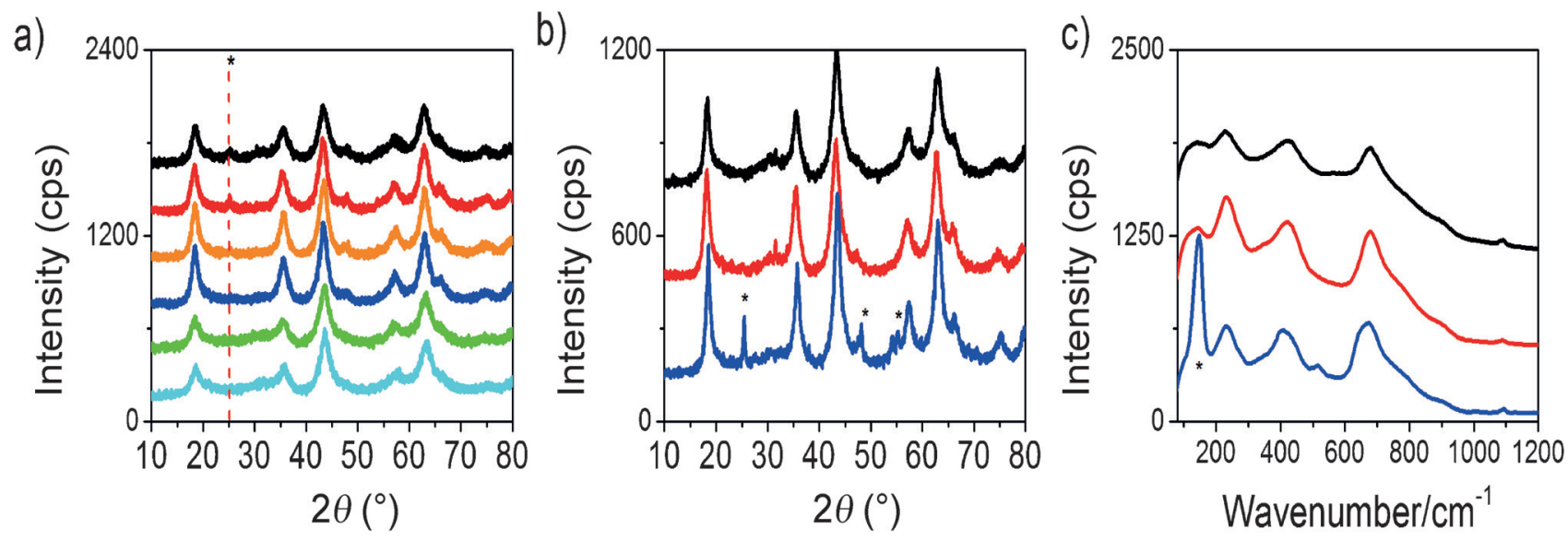

Figure 3. a) XRD patterns of samples calcined at $350^{\circ} \mathrm{C}$ and annealed at $450^{\circ} \mathrm{C}$ for $2 \mathrm{~h}$ for CAxx-350-450 samples ( $x x$ values are $20,36,40,52,60$, and 72 from top to bottom). b) XRD patterns of LTO samples of CA60-350-500 (top; calcined for 30 min and annealed for 30 min), CA60-500-500 in 50 min (middle; calcined from 150 to $500^{\circ} \mathrm{C}$ and annealed at $500^{\circ} \mathrm{C}$ for $30 \mathrm{~min}$ ), and C60-500 (bottom; directly calcined at $500^{\circ} \mathrm{C}$ for 30 min). c) Raman spectra of the same samples as those shown in b). 
the titania anatase phase. Notably, the calcination and annealing temperatures are also critical. For instance, Figure $3 \mathrm{~b}$ shows the XRD patterns of $\mathrm{C} 60$ calcined under 3 different conditions at $500^{\circ} \mathrm{C}$. Calcination directly at $500^{\circ} \mathrm{C}(\mathrm{C} 60-500)$ forces a phase separation into larger LTO nanocrystals and bulk titania. However, samples calcined at low temperature $\left(350^{\circ} \mathrm{C}\right.$, C60-350), then annealed at $500^{\circ} \mathrm{C}$ (CA60-350-500), and calcined slowly from 150 to $500^{\circ} \mathrm{C}$ (CA60-150-500) display similar diffraction patterns; no phase separation is detected by XRD. A similar trend was also observed in the Raman spectra of the above three samples. The bands observed at 680, 420, and $233 \mathrm{~cm}^{-1}$ are due to spinel LTO $[40,41]$ The shoulders on the high-energy side of the most intense band at $680 \mathrm{~cm}^{-1}$ are characteristic of surface peroxide species. Notably, characteristic Raman bands of LTO are enhanced and become sharper with crystallization (Figure S1 in the Supporting Information).

Both XRD and Raman data confirm that nanocrystalline LTO forms upon calcination of the lithium salt-pluronic mesophases. However, nitrogen-sorption measurements provide more detailed information regarding the pore systems of two samples: CA60-150-500 and C60-350-500 (Figure 4). Both samples a)

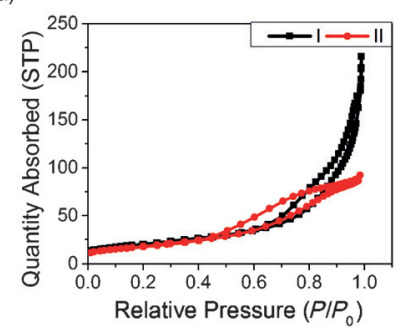

b)

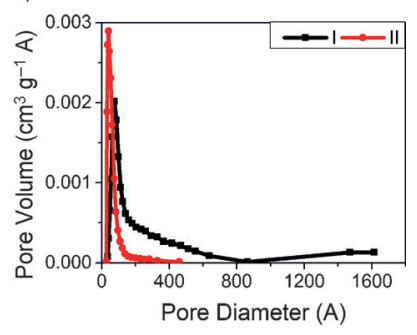

Figure 4. a) Nitrogen-sorption isotherms and b) pore size distribution plots of the samples: I) CA60-350-500 and II) CA60-150-500.

have similar surface areas, but very different pore size distributions. Heating slowly, from 150 to $500^{\circ} \mathrm{C}$, gives a much more uniform size distribution with a relatively smaller pore size (on average $3.9 \mathrm{~nm}$, obtained from the desorption branch); however, samples calcined at higher temperature and annealed at $500^{\circ} \mathrm{C}$ have smaller and larger pores $(7.6 \mathrm{~nm})$ with a nonuniform distribution. Therefore, it is reasonable to conclude that the calcination and annealing processes are critical in the synthesis of mesoporous LTO films. We also recorded the XRD, $\mathrm{N}_{2}$ sorption isotherms, and Raman spectra of sample CA60-350450 with increasing annealing times at a fixed temperature, at which growth is not dominating. The XRD pattern becomes more intense without changes to the full-width at half-maximum (FWHM) of the LTO diffraction lines with increasing annealing time at $450^{\circ} \mathrm{C}$ (Figure S1a in the Supporting Information).

The Raman spectra of these samples are very similar in their band positions, but the intensity of the main bands of LTO also increase over time (Figure S1b in the Supporting Information). However, the surface area gradually decreases over a period of $4.5 \mathrm{~h}$ from 125 to $95 \mathrm{~m}^{2} \mathrm{~g}^{-1}$, while very little changes are observed in the pore size and pore size distribu- tion (Figure S1c and d in the Supporting Information). All compositions, at all temperatures, produce nanocrystalline LTO as a single phase; however, annealing at higher temperatures improves the crystallinity. At around $550^{\circ} \mathrm{C}$, the mesopores start collapsing to yield larger LTO nanocrystallites. The crystallization process, at a given temperature, is also a kinetic process, through which crystallinity can be improved by keeping the temperature constant at around $450^{\circ} \mathrm{C}$, which, in effect, keeps the particle size more or less constant. Therefore, the annealing steps and duration can be controlled to optimize the surface area, pore size, pore size distribution, crystallinity, and so forth of the mesoporous LTO films.

We further optimized the reaction conditions to embed in situ carbon to protect the electrode surfaces from surface peroxides and to enhance the conductivity of the LTO. Calcination was carried out at a low temperature and the annealing step was carried out under vacuum; samples were labeled as CAxx$y y y-z z z-C$ (CA stands for calcined and annealed, $x x$ is the $\mathrm{Li}^{\prime}$ / P123 molar ratio, yyy is the calcination temperature, $z z z$ is the annealing temperature, and $C$ at the end of the label stands for carbon). These samples are black in color. Figure S2 in the Supporting Information shows the XRD and Raman data of carbon-containing LTO samples. Keeping carbons in the pores does not change the XRD pattern. Figure S2a in the Supporting Information shows the XRD patterns of two samples calcined at $350^{\circ} \mathrm{C}$ and annealed at 450 and $500^{\circ} \mathrm{C}$ under vacuum. Clearly, the sample annealed at $500^{\circ} \mathrm{C}$ is more crystalline or it consists of larger LTO nanocrystallites. The Raman spectra also display bands at 1354 and $1590 \mathrm{~cm}^{-1}$ due to partially graphitic carbon $^{[39,42]}$ embedded in the pores. The calcination and annealing temperatures are also important parameters in the carbon-containing samples (Figure S2b in the Supporting Information). For instance, the final annealing temperature determines the crystallinity, but the calcination temperature is also critical in determining the amount of carbon in the samples, the pore size, and the pore size distribution (Figure S2c and d in the Supporting Information). If calcination is carried out at a lower temperature, such as 250 versus $350^{\circ} \mathrm{C}$, the pore size distribution is more uniform and the pores are smaller, but the surface area is also smaller, which indicates that more carbon is present and that carbon species are blocking the pores (Figure $\mathrm{S} 2 \mathrm{c}$ and $\mathrm{d}$ in the Supporting Information). Although the final annealing temperatures are the same, sample CA60-250$450-C$ has $50 \%$ less surface area than that of the CA60-350$450-C$ sample. These observations are consistent with the above proposal.

TEM images of the samples were recorded (Figure 5) as ultrathin films. The films were coated at a spin rate of $5000 \mathrm{rpm}$ and calcined at $450^{\circ} \mathrm{C}$. The images show a spongelike porous structure. The low-magnification and large-area images show that the sample has a uniform pore morphology and is highly porous (Figure 5). The typical pore size is $4-10 \mathrm{~nm}$, which is also consistent with data from nitrogen-sorption measurements. Analysis of selected regions shows lattice fringes that correspond to LTO nanocrystallites. The lattice fringes in the upper part of the pores (see Figure 5, right) correspond to (311) planes at a $d$ spacing of $0.25 \mathrm{~nm}$, which is consistent with 


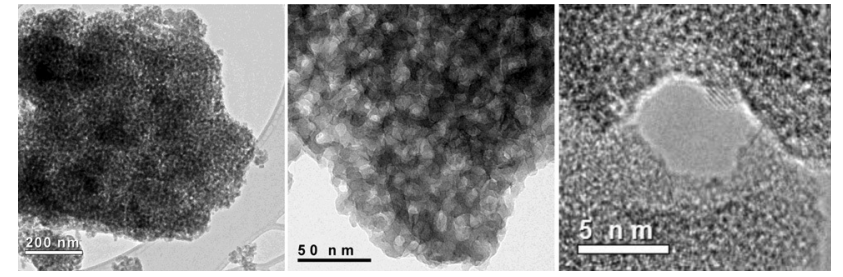

Figure 5. TEM images CA40-350-450 thin films at different magnifications.

XRD results. The measured pore wall thickness is around 5$6 \mathrm{~nm}$ and is consistent with the measured surface area and crystallite size $(4-5 \mathrm{~nm})$ obtained by using the Scherrer equation. We also recorded SEM images of calcined and annealed samples to show the substrate and mesoporous LTO film interface (Figure S3 in the Supporting Information). The SEM image clearly shows a nice contact between the substrate and LTO film, with a typical thickness of about $260-400 \mathrm{~nm}$.

Electrochemical characterization of the LTO materials, synthesized by changing the Li/P123 ratios, annealing temperatures, film thicknesses, surfactants, and carbon additives was also completed. By comparing different Lil/P123 ratios, the calcination and annealing temperatures were set to 350 and $450^{\circ} \mathrm{C}$, respectively. After all cells were initially cycled at $C / 2$ for 7 cycles, they were tested at $2 C$ for 50 cycles to observe their cyclic stability. The rate capabilities of the materials were then measured at various current rates, including $C / 2,2 C, 5 C$, $10 C, 20 C$, and $50 C$. Finally, 5 cycles at a current rate of $C / 2$ were applied to each material to see their final standing.

The electrochemical properties of the material change when the Li/P123 ratio is changed (see Figure 6 and Table 2). Notably, the electrochemical performance of the material increases as the ratio of $\mathrm{Li}^{\mathrm{l}} / \mathrm{P} 123$ increases from 28:1 to 40:1, but the performance starts to drop when the ratio is increased further to $52: 1$ and 60:1. The surface areas are similar in CA28-X $(x$ is $350-450)$ to CA40-X and gradually decrease from CA40-X to CA72-X, indicating thicker pore walls (see Table 1 ), which reduces the amount of material that is in direct contact with the electrolyte.

Among the materials tested, the CA40-350-450 sample, which was spin coated at a spin rate of $1750 \mathrm{rpm}$, displayed the best electrochemical performance (Figure 7). The material yielded a high irreversible discharge capacity in the first cycles

a)

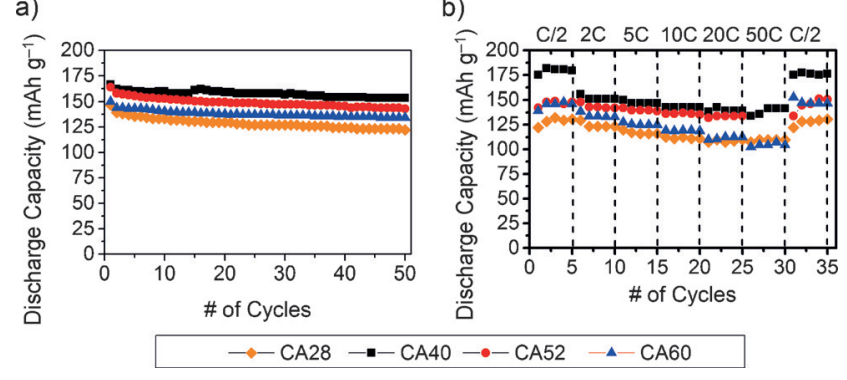

Figure 6. a) Cyclic stability at a current rate of $2 C$ for 50 cycles and b) rate capabilities of CA28-350-450, CA40-350-450, CA52-350-450, and CA60-350450.
Table 2. The average discharge capacity values at each step of the electrochemical measurements for CAxX-X ( $X$ is $350-450)$.

\begin{tabular}{lllll} 
& \multicolumn{4}{c}{ Average discharge capacity $\left[\mathrm{mA} \mathrm{h}^{-1}\right]^{[a]}$} \\
& $28-X$ & $40-X$ & $52-X$ & $60-X$ \\
\hline first $2 C$ in 50 cycles & 147 & 166 & 164 & 150 \\
last 2C in 50 cycles & 122 & 153 & 143 & 134 \\
first C/2 & $128 \pm 4$ & $180 \pm 3$ & $147 \pm 3$ & $145 \pm 3$ \\
$2 C$ & $125 \pm 3$ & $152 \pm 2$ & $144 \pm 2$ & $134 \pm 2$ \\
$5 C$ & $117 \pm 2$ & $148 \pm 1$ & $140 \pm 1$ & $125 \pm 1$ \\
$10 C$ & $111 \pm 1$ & $143 \pm 0$ & $136 \pm 1$ & $119 \pm 0$ \\
$20 C$ & $109 \pm 1$ & $140 \pm 2$ & $133 \pm 1$ & $112 \pm 1$ \\
$50 C$ & $109 \pm 1$ & $139 \pm 4$ & - & $104 \pm 2$ \\
last C/2 & $128 \pm 3$ & $176 \pm 1$ & $145 \pm 7$ & $148 \pm 3$ \\
\hline
\end{tabular}

[a] Values with no standard deviation indicate single measurements.

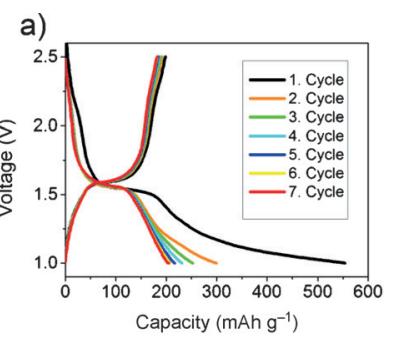

c)
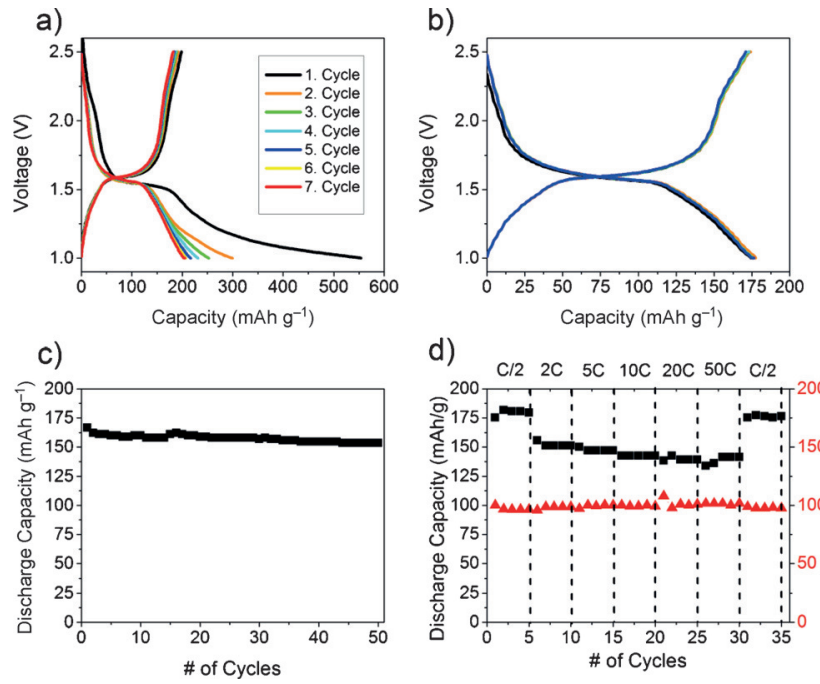

d)

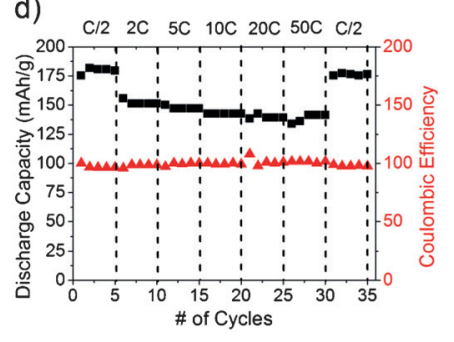

Figure 7. a) First 7 charge-discharge curves of CA40-350-450 at C/2. b) Last 5 charge-discharge curves of CA40-350-450 at C/2. c) Cyclic stability at a current rate of 2 C for 50 cycles. d) Rate capability of CA40-350-450.

due to thin pore walls and likely surface peroxides. Nevertheless, its discharge capacity, obtained after 92 cycles at various current rates, in the last 5 cycles was fixed at about $176 \mathrm{mAhg}^{-1}$ at a current rate of $\mathrm{C} / 2$; this value is comparable to the theoretical capacity of LTO $\left(175 \mathrm{mAhg}^{-1}\right)$. In terms of cyclic stability, the material was able to preserve $92 \%$ of its initial capacity after 50 cycles at 2 C. Furthermore, the CA40-350450 sample also provides an excellent rate capability by offering an average discharge capacity of $139 \mathrm{mAhg}^{-1}$ at a very high current rate of $50 \mathrm{C}$, which corresponds to $73.3 \%$ of its initial capacity at a current rate of $C / 2$ in the rate capability measurement. When the electrochemical performance of the material is compared with results reported in the literature, CA40$350-450$ showed a better rate capability $\left(139 \mathrm{mAhg}^{-1}\right.$ at $\left.50 \mathrm{C}\right)$ with a $20-30 \%$ higher discharge capacity than those of mesoporous LTO materials prepared by using various methods in the literature, ${ }^{[16,18,22,43]}$ a similar rate capability to mesoporous LTO thin film produced by using a large diblock copolymer (KLE, which consists of poly(ethylene-co-butylene)-poly(ethylene oxide) $),{ }^{[20]}$ and a worse rate capability than that of meso- 
porous LTO synthesized by solvothermal synthesis in tert-butanol. ${ }^{[21]}$ Large surface area, highly porous structure, and high crystallinity (4-6 nm domain size) are the likely reasons for the strong performance of the material because they provide excellent electronic conductivity and better contact (Figure S3 in the Supporting Information) between the electrolyte and electrode surface, and consequently, increase the $\mathrm{Li}^{+}$ion conductivity. To elucidate the effect of contact resistance of the CA40350-450 sample, the electrochemical impedance spectra of this sample before and after annealing at $600^{\circ} \mathrm{C}$ (bulk form of LTO) were also recorded. The results are presented with Nyquist plots in Figure S4 in the Supporting Information. The chargetransfer resistance of CA40-350-450 is inferior to that of the bulk electrode because the diameter of the semicircle in the high-frequency region is drastically smaller for CA40-350-450 than that of the bulk form; this correlates with the superior rate performance of CA40-350-450. However, further studies should be performed to determine the exact reasoning.

We also investigated the thickness-dependent electrochemical performance of the LTO films (Figure S5 in the Supporting Information). The thickness of the films can be controlled either by changing the viscosity of the initial clear solution through variation in the $\left(\mathrm{Li}^{\mathrm{l}}+\mathrm{Ti}^{\mathrm{IV}}\right) / \mathrm{P} 123$ ratio or by controlling the spin speed during the coating process. Both approaches were tested by preparing thin films at two different spin speeds $(1300 \mathrm{rpm}$ for thick samples and $3000 \mathrm{rpm}$ for thin samples; at lower speeds the films crack) for two different samples (CA40-350-450 and CA60-350-450). The thicker CA40350-450 sample performed very similar to the thin CA60-350450 sample. However, the thinner CA60-350-450 sample performed better than its thicker counterpart, but both the rate capability and cyclic stability of the CA60-35-450 samples were slightly worse than that of the CA40-350-450 samples (Figure S5 in the Supporting Information).

The effects of various annealing temperatures were also tested, and the results are shown in Figure S6 and Table S1 in the Supporting Information. Although the initial capacity values of CA60-350-350 were higher than those of CA60-350450 , the final capacity values at the end of the cyclic stability and rate capability tests were very similar. This result indicates that the stability and capacity retention of CA60-350-450 are higher than those of CA60-350-350. Additionally, the average discharge capacity of CA60-350-550 was highest when compared with CA60-350-450 and CA60-350-350. It is difficult to explain the improved discharge capacity, since the sample undergoes structural changes, starting at around $550^{\circ} \mathrm{C}$. Furthermore, it was shown in earlier characterizations that the pores of the material, annealed at $550^{\circ} \mathrm{C}$, partially collapsed and caused a significant reduction in the surface area and pore volume to produce a bulk-like structure. Thus, the plateau becomes clearer in the voltage versus discharge capacity plots (Figure S6 in the Supporting Information). The CA60 samples also contain some $\mathrm{TiO}_{2}$ (anatase) that further crystallizes upon annealing over $500^{\circ} \mathrm{C}$ (see Figure $3 \mathrm{~b}$ ). This could be the reason for the formation of a second plateau at about $2.07 \mathrm{~V}$ during charging (Figure 3 and Figure S7 in the Supporting Information). Further investigation may be necessary to fully elu- cidate the origin of the second plateau and improved capacity performance.

Mesoporous LTO materials were also prepared by burning the surfactant under vacuum conditions to generate in situ carbon in the pores. Although LTO is known for its SEl-free surface, we observed some irreversible discharge capacity in the materials during the first few cycles. As mentioned earlier, this was likely to be due to thin pore walls and surface peroxides. Although the electronic conductivities of the LTO films are already excellent and there is no need to further boost the conductivity, the carbon coating helps to prevent the irreversible discharge capacity, as observed in the initial cycles. Figure 8 shows that there is almost no SEl formation in the first chargedischarge cycles of the CA60-350-450-C film. The open-circuit potential of the CA60-350-450-C film was reduced to about $1.5 \mathrm{~V}$. This was expected because carbon offered a lower potential difference against the $\mathrm{Li}^{+} / \mathrm{Li}$ electrode. ${ }^{[7]}$ It also provided a lower capacity during cyclic stability and rate capability measurements, which could be explained by the additional inactive weight of carbon present in the structure. a)

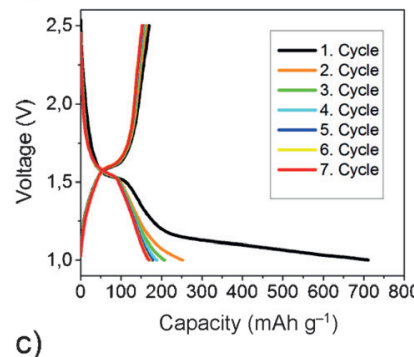

c)

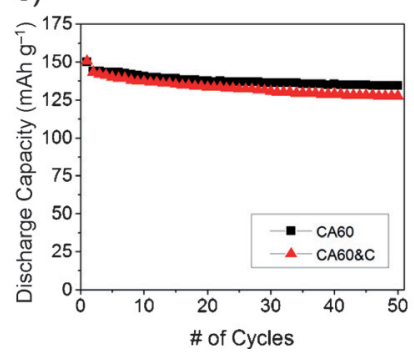

b)

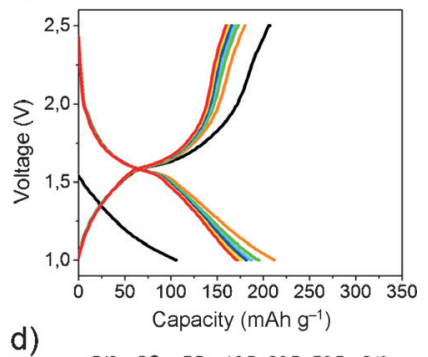

d)

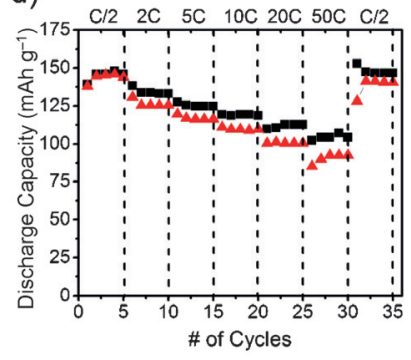

Figure 8. a) First 7 charge-discharge curves of $C A 60-350-450$ at $C / 2$. b) First 7 charge-discharge curves of CA60-350-450-C at C/2. c) Cyclic stabilities at a current rate of $2 C$ for 50 cycles. d) Rate capabilities of CA60-350-450 and CA60-350-450-C.

The electrode materials, synthesized by using P123, are expected to have larger pores and better crystalline pore walls than those synthesized with oligo(ethylene oxide) surfactants and provide a better electrochemical performance in LIBs. To prove that claim, film samples of CA28-350-450, CA40-350-450, and LTO1 (prepared from $\mathrm{C}_{12} \mathrm{E}_{10}, \mathrm{CTAB}$, and $\mathrm{Li} / \mathrm{C}_{12} \mathrm{E}_{10}$ with a molar ratio of 4) were electrochemically analyzed and compared (Figures S8 and S9 in the Supporting Information). Among the materials synthesized by using P123 and CTAB, CA28-350-450 has the closest structure to that of LTO1 because the wall thickness and pore size of the material are expected to be similar. Even with the smallest Li'/P123 ratio of 
28, the material synthesized by using $\mathrm{P} 123$ and CTAB yielded a better electrochemical performance than that synthesized by using $\mathrm{C}_{12} \mathrm{E}_{10}$ and $C T A B$ (compare plots in Figures $\mathrm{S} 8$ and $\mathrm{S} 9$ in the Supporting Information). The origin of this difference between the two materials may be due to larger pores and thicker and better crystalline walls in samples prepared by using P123. Furthermore, the overpotential observed during the first charge of LTO1 is the highest among the tested materials. The results confirm the superiority of the LTOs synthesized by using the P123/CTAB couple.

\section{Conclusion}

The MASA process is a useful method to prepare thin films of mesoporous LTOs. The process starts with a clear solution of all ingredients (surfactants, salt, titania source, acid, and ethanol) that can be coated over any substrate at a desired thickness, at which point the calcination and annealing processes produce highly transparent mesoporous thin films. The stable mesoporous films can be prepared over a broad range of $\mathrm{Li}^{\mathrm{l}}$ / P123 molar ratios (28-72) by keeping the $\mathrm{Li}^{\mathrm{l}} / \mathrm{Ti}^{\mathrm{iV}}$ molar ratio constant ( 0.8 , stoichiometric ratio). A high CTAB concentration is also necessary to prepare stable LTOs with a spinel structure at high inorganic/organic ratios. The typical pore size in the final materials varies from 4 to $6 \mathrm{~nm}$, but it can be expanded by further annealing at higher temperatures. The surface area is quite large and is dependent on composition and temperature; the typical surface area and pore volumes vary between 163 and $139 \mathrm{~m}^{2} \mathrm{~g}^{-1}$ and 0.76 and $0.23 \mathrm{~cm}^{3} \mathrm{~g}^{-1}$, respectively. The LTO films can be directly deposited on stainless-steel current collectors through the spin-coating technique. Notably, even without using precious metal ${ }^{[17]}$ or carbon additives, ${ }^{[12,14-17]}$ a high cyclic stability (preserving $92 \%$ of its capacity in 50 cycles at a current rate of $2 C$ ), and a very high rate capability $\left(139 \mathrm{~mA} \mathrm{~h}^{-1}\right.$ average discharge capacity at a current rate of 50C) were achieved from the CA40-350-450 film. The MASA synthetic method offers a promising path to produce various $\mathrm{Li}$-containing porous thin film electrodes for LIB applications.

\section{Experimental Section}

\section{Materials}

Lithium bis(trifluoromethanesulfonyl) imide (LiTFSI), titania source, surfactants, ethanol, battery-grade ethylene carbonate (EC), and dimethyl carbonate (DMC) were purchased from Sigma-Aldrich and used without further treatment. Celgard C480 membrane was purchased from Celgard. Glass microfiber filter (GF/C) was purchased from Whatman.

\section{Synthesis of mesoporous LTO}

In the first step, clear solutions of the ingredients were prepared by keeping all ingredient ratios constant and only varying those of $\mathrm{LiNO}_{3}$ and TTB, with a $\mathrm{Li}^{1} / \mathrm{Ti}^{\mathrm{iV}}$ molar ratio of 0.8 , which was a stoichiometric ratio in LTO (see Table 3 for details of the compositions). For example, the sample with a Li//P123 molar ratio of 60 was prepared as follows. First, $\mathrm{LiNO}_{3}$ was dissolved $(571 \mathrm{mg})$ in ethanol $(7.6 \mathrm{~g})$. Then, with $5 \mathrm{~min}$ time intervals, CTAB $(638 \mathrm{mg})$, P123
Table 3. All ingredients of 6 different compositions of the clear solutions used in sample preparation with a constant $\mathrm{Li}^{\mathrm{i}} / \mathrm{Ti}^{\mathrm{iV}}$ molar ratio of 0.8 and varying $\mathrm{Li}^{\mathrm{l}} / \mathrm{P} 123$ and $\mathrm{Ti}^{\mathrm{IV}} / \mathrm{P} 123$ molar ratios.

\begin{tabular}{|lllll|}
$\begin{array}{l}\mathrm{Li} / \mathrm{Ti}^{\mathrm{IV}} / \mathrm{P} 123 \\
\text { molar ratio }\end{array}$ & $\begin{array}{l}\mathrm{LiNO}_{3} \\
{[\mathrm{mg}]}\end{array}$ & $\begin{array}{l}\mathrm{TTB} \\
{[\mathrm{mg}]}\end{array}$ & $\begin{array}{l}\mathrm{P} 123 \\
{[\mathrm{mg}]}\end{array}$ & $\begin{array}{l}\mathrm{CTAB} \\
{[\mathrm{mg}]}\end{array}$ \\
\hline $28: 35: 1$ & 241 & 1498 & 719 & 638 \\
36:45:1 & 310 & 1915 & 719 & 638 \\
$40: 50: 1$ & 345 & 2127 & 719 & 638 \\
$52: 65: 1$ & 448 & 2765 & 719 & 638 \\
$60: 75: 1$ & 571 & 3191 & 719 & 638 \\
$72: 90: 1$ & 621 & 3829 & 719 & 638 \\
\hline
\end{tabular}

(719 mg), $\mathrm{HNO}_{3}(550 \mathrm{mg})$, and TTB (3.191 g) were sequentially added to the above clear solution and stirred for another hour. Then, a few drops of the above clear solution was put on a glass substrate that was placed over a spin coater and spun for $10 \mathrm{~s}$ at $1500 \mathrm{rpm}$ to form thin films. Thicker LTO films were prepared by depositing the transparent solution on glass substrates by means of pressurized dry air (spray-coating method). Subsequently, the gel-like films were immediately inserted into a preheated oven for calcination at $350^{\circ} \mathrm{C}$ and annealing at various temperatures (see below).

\section{Characterization}

XRD patterns were recorded on a Rigaku Miniflex diffractometer by using a high-power $\mathrm{Cu}_{\mathrm{k} \alpha}$ source operating at $30 \mathrm{kV} / 15 \mathrm{~mA}$. The diffraction patterns were collected from fresh samples by either spin or spray coating over microscope slides and calcined powder samples, obtained from spray coating. The patterns were collected at both small $\left(2 \theta=1-5^{\circ}\right)$ and high angles $\left(2 \theta=10-80^{\circ}\right)$ with a step size of $0.01^{\circ}$ and scan speed of $1^{\circ} \mathrm{min}^{-1}$. The micro-Raman spectra were recorded on a LabRam confocal Raman microscope with a focal length of $300 \mathrm{~mm}$. The spectrometer was equipped with a Ventus LP $53250 \mathrm{~mW}$ diode-pumped solid-state laser operated at $20 \mathrm{~mW}$, with a polarization ratio of 100:1 and a wavelength of a $532.1 \mathrm{~nm}$, equipped with a $1024 \times 256$ element charge-coupled device (CCD) camera. The signal collected was transmitted through a fiber-optic cable into a spectrometer with a grating of $600 \mathrm{~g} \mathrm{~mm}^{-1}$. The Raman spectra were collected by manually placing the probe tip on the desired point of the sample on a glass slide. The $\mathrm{N}_{2}(77.4 \mathrm{~K})$ sorption measurements were carried out by using a TriStar 3000 automated gas adsorption analyzer (Micrometrics) over a relative pressure range, $P / P_{\mathrm{o}}$, from 0.01 to 0.99 . To provide high accuracy and precision in the determination of $P / P_{0}$, the saturation pressure, $P_{\mathrm{o}}$, was measured over $120 \mathrm{~min}$ intervals. The powder samples, which were obtained by scraping spray-coated thick films, were dehydrated under (ca. 50 mtorr) vacuum for $3 \mathrm{~h}$ at $250^{\circ} \mathrm{C}$ to remove adsorbed water and other volatile species from the pores before the $\mathrm{N}_{2}$ sorption measurements were performed. TEM images were recorded by using an FEI Tecnai G2 F30 microscope. The samples were prepared by being first ground in a small amount of ethanol and dispersed in ethanol $(5 \mathrm{~mL})$ and sonicated for 10-15 min to ensure dispersion of the particles, and then a few drops of this solution was dropped over the thin carbon-coated TEM grid and dried under an intense light to prevent aggregation. For electrochemical characterization, mesoporous LTO thin-film electrodes were prepared by coating stainless-steel current collectors with the abovementioned clear solution. To coat the steel current collectors, which were installed over a spin coater, three drops of the solution were put on them and spun at different speeds for varying times, according to the desired thicknesses. The prepared 
films were immediately placed into the preheated furnace. The films were calcined at $350^{\circ} \mathrm{C}$ for $30 \mathrm{~min}$ and then annealed at various temperatures $\left(350-550^{\circ} \mathrm{C}\right)$ and durations $(30-270 \mathrm{~min})$.

\section{LIB preparation}

The electrode materials were rapidly put into an argon-filled glovebox $\left(\mathrm{O}_{2}<0.5 \mathrm{ppm}, \mathrm{H}_{2} \mathrm{O}<0.5 \mathrm{ppm}\right)$ to prevent air exposure and assembled against lithium metal electrodes in Swagelok-type cells in which the stainless-steel substrates were used as current collectors of the cathodes and anodes. Celgard C480 separators were utilized at the $\mathrm{Li}$ anode sides, whereas the separators of the cathode sides were GF/C. The electrolyte solutions of the cells were composed of $0.5 \mathrm{M}$ LiTFSI $(280 \mu \mathrm{L})$ dissolved in EC/DMC $(1: 1)$. The cells were sealed after assembly to prevent interactions with the atmosphere, and rested at room temperature for $11 \mathrm{~h}$ prior to testing.

\section{Multichannel battery testing system}

For electrochemical testing, a Landt CT2001A multichannel potentiostat/galvanostat was employed. Different current rates $(C / 2,2 C$, $5 C, 10 C, 20 C$, and $50 C$ ) were applied in the voltage range of $1-$ $2.5 \mathrm{~V}$. The capacity and current rate calculations were performed according to the dry weight of the LTO materials (typical weights of the films were $0.1-0.2 \mathrm{mg}$ ) spin coated on the current collectors and the theoretical capacity of LTO $\left(1 \mathrm{C}=175 \mathrm{mAhg}^{-1}\right)$.

\section{Acknowledgements}

This work was funded by TÜBITAK grant no. 113Z730. F.M.B. thanks TÜBITAK for financial support under grant no. $113 Z 730$. Ö.D. is a member of the Academy of Science, Istanbul.

Keywords: electrochemistry · lithium - mesoporous materials · self-assembly • thin films

[1] S. Guo, S. Dong, Chem. Soc. Rev. 2011, 40, 2644.

[2] J. M. Tarascon, M. Armand, Nature 2001, 414, 359.

[3] S. M. Hwang, Y.-G. Lim, J.-G. Kim, Y.-U. Heo, J. H. Lim, Y. Yamauchi, M.-S. Park, Y.-J. Kim, S. X. Dou, J. H. Kim, Nano Energy 2014, 10, 53.

[4] M. Pramanik, Y. Tsujimoto, V. Malgras, S. X. Dou, J. H. Kim, Y. Yamauchi, Chem. Mater. 2015, 27, 1082.

[5] H. Xue, J. Zhao, J. Tang, H. Gong, P. He, H. Zhou, Y. Yamauchi, J. He, Chem. Eur. J. 2016, 22, 4915.

[6] L. Shen, X. Zhang, E. Uchaker, C. Yuan, G. Cao, Adv. Energy Mater. 2012, 2, 691 .

[7] L. Zhao, Y. S. Hu, H. Li, Z. Wang, L. Chen, Adv. Mater. 2011, 23, 1385.

[8] L. Shen, E. Uchaker, X. Zhang, G. Cao, Adv. Mater. 2012, 24, 6502.

[9] M.-S. Song, A. Benayad, Y.-M. Choi, K.-S. Park, Chem. Commun. 2012, 48, 516.

[10] Y. Shi, L. Wen, F. Li, H. M. Cheng, J. Power Sources 2011, 196, 8610.
[11] Y. Sun, L. Zhao, H. Pan, X. Lu, L. Gu, Y.-S. Hu, H. Li, M. Armand, Y. Ikuhara, L. Chen, X. Huang, Nat. Commun. 2013, 4, 1870.

[12] J. Liu, K. Song, P. A. Van Aken, J. Maier, Y. Yu, Nano Lett. 2014, 14, 2597.

[13] Y. Tang, L. Yang, Z. Qiu, J. Huang, J. Mater. Chem. 2009, 19, 5980.

[14] W. Chen, H. Jiang, Y. Hu, Y. Dai, C. Li, Chem. Commun. 2014, 50, 8856.

[15] Y. Tang, F. Huang, W. Zhao, Z. Liu, D. Wan, J. Mater. Chem. 2012, 22, 11257.

[16] L. Sun, W. Kong, H. Wu, Y. Wu, D. Wang, F. Zhao, K. Jiang, Q. Li, J. Wang, S. Fan, Nanoscale 2016, 8, 617.

[17] W. Wang, Y. Guo, L. Liu, S. Wang, X. Yang, H. Guo, J. Power Sources 2014, 245, 624 .

[18] E. Kang, Y. S. Jung, G. H. Kim, J. Chun, U. Wiesner, A. C. Dillon, J. K. Kim, J. Lee, Adv. Funct. Mater. 2011, 21, 4349.

[19] J. Lee, Y. S. Jung, S. C. Warren, M. Kamperman, S. M. Oh, F. J. Disalvo, U. Wiesner, Macromol. Chem. Phys. 2011, 212, 383.

[20] J. Haetge, P. Hartmann, K. Brezesinski, J. Janek, T. Brezesinski, Chem Mater. 2011, 23, 4384.

[21] J. M. Feckl, K. Fominykh, M. Döblinger, D. Fattakhova-Rohlfing, T. Bein, Angew. Chem. Int. Ed. 2012, 51, 7459; Angew. Chem. 2012, 124, 7577.

[22] L. Yu, H. B. Wu, X. W. Lou, Adv. Mater. 2013, 25, 2296.

[23] C. Avcl, A. Aydın, Z. Tuna, Z. Yavuz, Y. Yamauchi, N. Suzuki, Ö. Dag, Chem. Mater. 2014, 26, 6050.

[24] C. Karakaya, Y. Türker, C. Albayrak, Ö. Dag, Chem. Mater. 2011, 23, 3062

[25] C. Karakaya, Y. Türker, Ö. Dag, Adv. Funct. Mater. 2013, 23, 4002.

[26] Ö. Çelik, Ö. Dag, Angew. Chem. Int. Ed. 2001, 40, 3799; Angew. Chem. 2001, 113, 3915.

[27] A. F. Demirörs, B. E. Eser, Ö. Dag, Langmuir 2005, 21, 4156.

[28] C. Albayrak, N. Özkan, Ö. Dag, Langmuir 2011, 27, 870.

[29] C. Albayrak, G. Barım, Ö. Dag, J. Colloid Interface Sci. 2014, 433, 26.

[30] N. M. Selivanova, A. B. Konov, K. A. Romanova, A. T. Gubaidullin, Y. G. Galyametdinov, Soft Matter 2015, 11, 7809.

[31] C. Albayrak, A. Cihaner, Ö. Dag, Chem. Eur. J. 2012, 18, 4190.

[32] C. Albayrak, A. M. Soylu, Ö. Dag, Langmuir 2008, 24, 10592.

[33] Y. Shi, Y. Wan, D. Zhao, Chem. Soc. Rev. 2011, 40, 3854.

[34] P. D. Yang, D. Y. Zhao, D. I. Margolese, B. F. Chmelka, G. D. Stucky, Nature $1998,396,152$

[35] D. Grosso, C. Boissière, B. Smarsly, T. Brezesinski, N. Pinna, P. A. Albouy, H. Amenitsch, M. Antonietti, C. Sanchez, Nat. Mater. 2004, 3, 787.

[36] A. H. Lu, F. Schüth, Adv. Mater. 2006, 18, 1793.

[37] H. Yen, Y. Seo, R. Guillet-Nicolas, S. Kaliaguine, F. Kleitz, Chem. Commun. 2011, 47, 10473.

[38] J. N. Israelachvili, D. J. Mitchell, B. W. Ninham, J. Chem. Soc. Faraday Trans. 2 1976, 72, 1525.

[39] R. Nagarajan, Langmuir 2002, 18, 31.

[40] L. Aldon, P. Kubiak, M. Womes, J. C. Jumas, J. Olivier-Fourcade, J. L. Tirado, J. I. Corredor, C. Pérez Vicente, Chem. Mater. 2004, 16, 5721.

[41] R. Baddour-hadjean, J.-P. Pereira-Ramos, Chem. Rev. 2010, 110, 1278.

[42] Y. Wang, D. C. Alsmeyer, R. L. McCreery, Chem. Mater. 1990, 2, 557.

[43] S. Chen, Y. Xin, Y. Zhou, Y. Ma, H. Zhou, L. Qi, Energy Environ. Sci. 2014, $7,1924$.

Received: September 8, 2016

Accepted Article published: October 23, 2016

Published online on November 18, 2016 